\title{
Raman Spectroscopy for Noninvasive Monitoring of Umbilical Cord Mesenchymal Stem Cells Viability Transitions
}

\author{
P. Chen ${ }^{1}$, F. Zhang ${ }^{1}$, L. Lin' ${ }^{1}$, H. Bai1, L. Zhang1,2, G. Q. Tang', H. Fang', \\ G. G. Mu1, W. Gong', Z. P. Liu'3 , Z. B. Han', H. Zhao ${ }^{3,4}$ and Z. C. Han 3,5
}

\section{Introduction}

As a burgeoning research area, stem cells' unique self-renewal and multilineage differentiation capability have quickly attracted the attention of scientists and researchers worldwide. Promising applications of stems cells include repairing and regenerating diseased or aged tissues and organs, restoring impaired body functions, and providing new treatments to various diseases.

One member in the stem cell family that deserves special mention is human umbilical cord derived mesenchymal stem cells (hUC-MSC). Great clinical application value and broad industrial development prospect of hUC-MSC have been recognized due to its large differentiation potential, strong proliferation capability, low immunogenicity, source variety, convenient availability, free of ethical restriction, and easy production in industry. Obviously, these unique features of stem cells rely on various factors including their biological composition, structure, and cell viability. The viability decrease, apoptosis, or necrosis of stem cells will seriously lead to the variation or even loss of their functions. Therefore, a key step in the production and quality control of stem cells is to accurately monitor the status of stem cells and their viability in real time. Research in this field has shown great importance in not only fundamental study of stem cell biology, but also research, development, and clinical use of stem cell drugs.

Although contemporary cell biology has provided a number of ways to acquire the information on the status of the cells, these methods are often invasive. Relevant biochemical reactions, dyeing, marking, fixation, cell lysis, and other treatments could remarkably induce the change of the environment necessary for cell growth and the normal physiological function of the cells. These biological techniques could even destroy the structures of the cells, leading to irreversible cell damage or necrosis. As a result, biology-based methods can hardly meet the requirements for the production and quality control of stem cells.

\footnotetext{
${ }^{1}$ Key Laboratory of Optoelectronic Information Science and Technology, Ministry of Education of China, Institute of Modern Optics, Nankai University, Tianjin 300071, China

${ }^{2}$ Department of Chemistry, University of Pennsylvania, Philadelphia, PA 19104-6323, U.S.A

${ }^{3}$ National Engineering Research Centre of Cell Products, Tianjin Economic and Development Area, China

4 Tianjin Key Laboratory of Food Biotechnology, Tianjin University of Commerce, Tianjin 300134, China

${ }^{5}$ The State Key Laboratory of Experimental Hematology, Institute of Hematology and Hospital of Blood Diseases, Chinese Academy of Medical Sciences and Peking Union of Medical College, Tianjin 300020, China
} 
Raman spectroscopy has prominent advantages over biological methods due to its high sensitivity to changes inside biological systems and influences from external environment. Also, it plays non-destructively on the cells. These distinguished features make Raman spectroscopy a superior choice in the study of high spatial resolution and real time monitoring of stem cells.

In this chapter, we will first introduce the basic concepts and theories of light absorption and scattering, and Raman scattering. Then, the change of the stem cell viability and its related mechanisms studied by Raman spectroscopy will be described in detail. Finally, a summary of our overall work will be given.

\section{Basic concept and elementary theory}

\subsection{Scattering and light scattering}

Scattering is a phenomenon widely seen in nature. When the incident particles collide with target particles, the incident particles interact with the target particle making the incident particles deviating from the incident direction and even changing its energy. This phenomenon is known as scattering. Analyzing the interactions of matters and their internal structures and movements by scattering has become an important tool in both macro and micro worlds.

Scattering of light is often observed in our daily lives. For example, when the light passes through a homogeneous and transparent matter such as glass and water, we cannot notice the light path from the side. However, if the media is inhomogeneous or contains impurities (like liquid with suspended particles or gels), the light beam can be clearly observed in the medium. This results from the scattering of light.

In the 19th century, the study of light scattering was focused on liquid and gas, which are widespread in nature. Based on the causes, the scatterings are classified as Tyndall scattering and molecular scattering. British physicist Lord Rayleigh studied the intensities of scattered molecular light. In 1871, he proposed that the intensity of scattered light is inversely proportional to the fourth powers of the wavelength $\left(\lambda^{4}\right)$. He proposed that the intensity of scattered light is inversely proportional to the fourth powers of the wavelength, which is known as the famous Rayleigh scattering law. In 1908, C. Mie found that the intensity of scattered light in Tyndall scattering is not inversely proportional to the fourth powers of the wavelength, which is in contrary to molecular scattering. Therefore, Tyndall scattering is also called Mie scattering.

Since the 20th century, the study of light scattering reached deeply into the levels of atoms, electrons, and quasi-particles. Researchers began to pay attention to the energy change of the scattered light relative to the incident light (i.e., the wavelength change). It was found that the wavelength variation of the scattered light relative to the incident light corresponds to different scattering mechanisms. The types of light scattering are thus classified. In the study of light scattering, the unit of energy is commonly the wave numbers $\left(\mathrm{cm}^{-1}\right)$.When the wave number change is less than $10^{-5} \mathrm{~cm}^{-1}$, the scattering is called Rayleigh scattering. Wave number change of about $0.1 \mathrm{~cm}^{-1}$ is called Brillouin scattering. More than $1 \mathrm{~cm}^{-1}$ wave number change is known as Raman scattering. If the wavelength / energy of the scattered light does not change relative to the incident light, it is elastic scattering, otherwise is nonelastic scattering. Obviously, the latter two types of scattering are non-elastic scattering. The wave number change in Rayleigh scattering is caused by the rebound of the target particles, and therefore Rayleigh scattering is elastic scattering. 


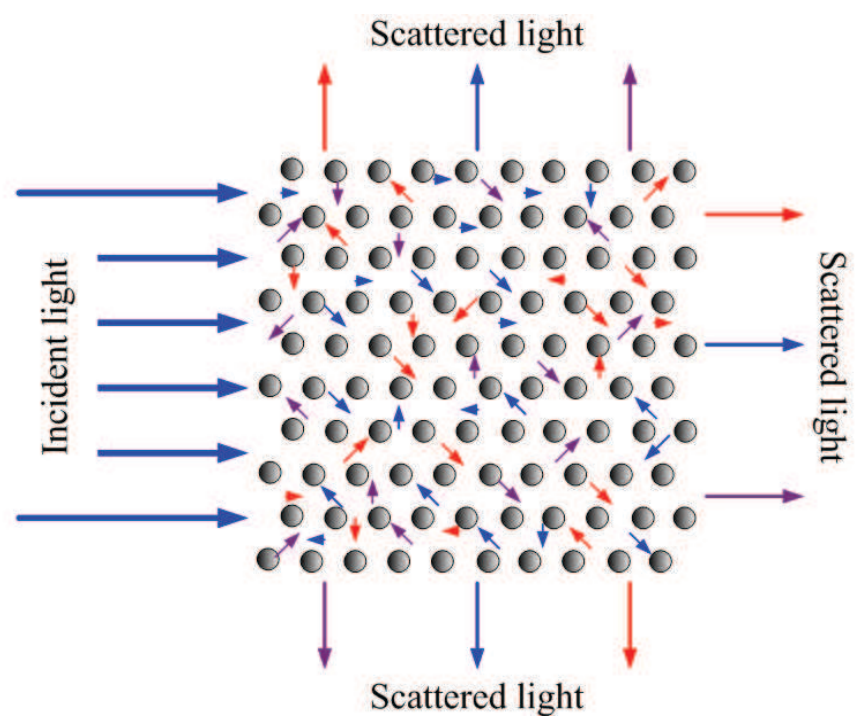

Fig.1. Scattering of light

\subsection{Raman scattering}

Raman spectroscopy is a scattering spectroscopy that concerns the vibrational and rotational energy levels of the molecules. It is a useful tool for the analysis of molecular structure, with advantages of being non-destructive and without the need of special ways to prepare the samples. Compared with the infrared absorption spectroscopy, water shows extremely weak Raman signals. Thus for most samples in water, the noise from water can be greatly reduced. Raman spectroscopy can also record signals from different samples in the same time, and these signals do not interfere with each other. With the developments of laser technology and weak signal detection technology, Raman spectroscopy as an effective method to study the structure of matter, will find wide and practical applications in various fields including chemistry, physics, biology, and medicine.

From the basic perspective of quantum theory, Raman scattering can be considered as an inelastic process as a result of the collisions between photons and molecules. When the incident photons collide with molecules, molecules interact with the photons and then absorb the photon energies. Molecules are thus excited into a virtual state. Since this virtual state is not stable, molecules immediately radiate photons and release energy. If the energy of the photon radiation is smaller than that of the incident photon, Stokes shift will be observed (Fig.2a). If the energy of photon radiation is larger than that of the incident photon, anti-Stokes shift will be recorded (Fig.2b). If the energy of photon radiation is equal to that of the incident photon, Rayleigh scattering will be produced (Fig.3). Since Raman scattering concerns the energy difference between the incident and scattered photons, this energy difference is associated with the corresponding vibration levels of the molecules.

Since each substance has rich vibration levels, Raman spectra carry a lot of information about the materials. Known as the fingerprint spectrum, Raman spectroscopy is of great significance to the analysis and identification of the components of materials. 


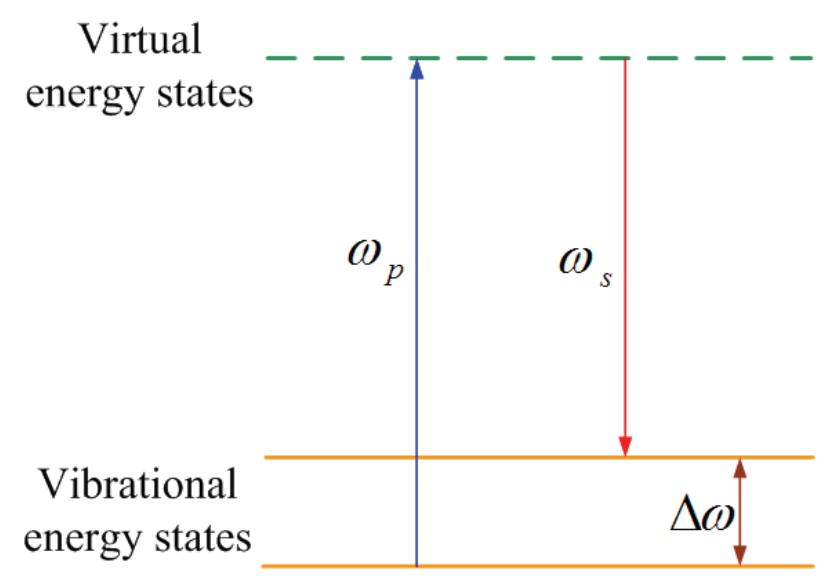

Fig. 2a. Raman scattering (Stokes effect)

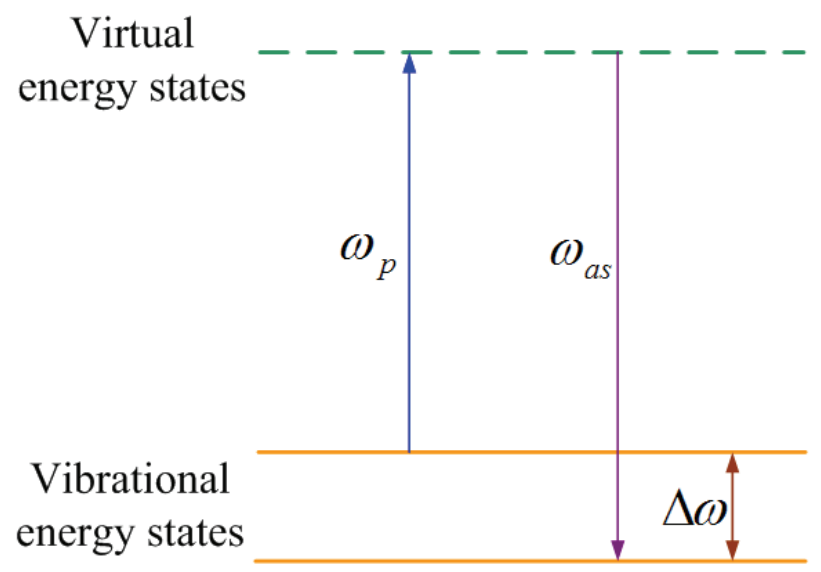

Fig. 2b. Raman scattering (Anti-Stokes effect) 


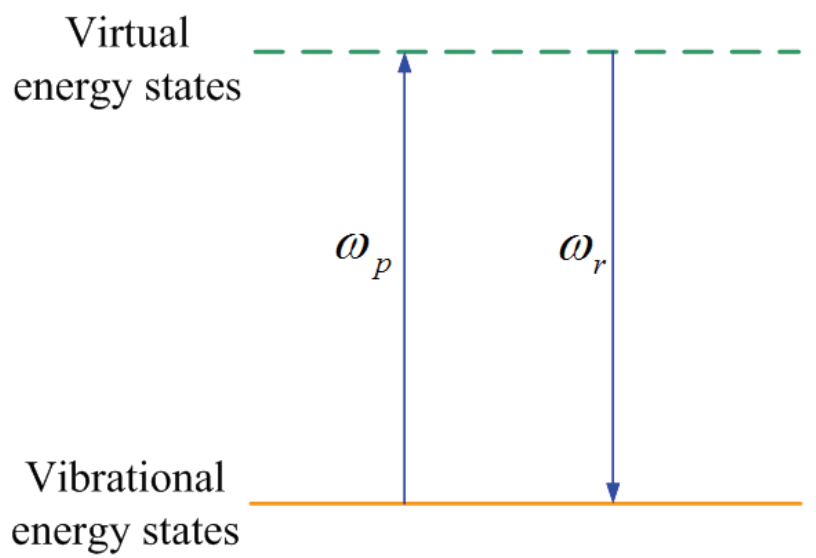

Fig. 3. Rayleigh scattering

\section{Detecting viability transitions of umbilical cord mesenchymal stem cells by Raman micro-spectroscopy}

Mesenchymal stem cells (MSCs) are pluripotent progenitor cells derived from the mesoderm. They are particularly attractive in cell/gene therapy for tissue regeneration and cancer therapy [1] for their own specific properties, including multi-differentiation potential, hematopoietic-supporting activity, immunomodulatory potency, and self-renewal. The major source of MSCs is bone marrow. However, the clinical use of bone marrow-derived MSCs is limited due to the relatively invasive sample collection procedure, and a significant reduction in cell number, proliferation, and differentiation capacity with age or age-related diseases. Recent advances suggest that human umbilical cord-derived mesenchymal stem cells (hUC-MSCs) could be an alternative source ideal for MSCs due to the relative ease of collection, safety, and abundance of human umbilical cord [2-5].

Our group has developed a standard procedure to acquire hUC-MSCs and established the first hUC-MSCs bank in China. Our intensive studies on the possible clinical application of this type of cells suggest that they can work as a promising candidate for cell-based therapy because of their young age and low infection rate compared to MSCs in adult tissues [6-9]. A large population of hUC-MSCs sustained in high viability condition is fundamental to successful cell-based therapy. Therefore, monitoring the cellular state transitions is an important step for the population expansion and quality assurance of these cells.

Currently, a number of methods including biological assays and optical techniques are available to handle this task. For example, laser scanning confocal fluorescence microscopy has been used to image living cells. However, the introduction of exogenous fluorescence labels is always a problem in the cell viability maintenance. On the contrary, Raman spectroscopy is a label-free, vibration spectroscopy-based technique that has been used to illustrate the intrinsic molecular structure and composition of biological samples. It has the potential to provide new and unique optical markers for cytological analysis in recent years [10-18]. At the present time, this technique has been increasingly used in the studies of stem cells. Notingher et al. monitored the differentiation of embryonic stem cells (ESCs) by 
recording the intensity of Raman peaks of nucleic acids as differentiation markers [19]. Chan et al. demonstrated that cell identification and classification were achieved using Raman scattering of the intrinsic biochemical signature for individual human embryonic stem cells (hESCs) [20]. More recently, Chiang and co-workers successfully applied Raman spectroscopy to monitor and quantitatively evaluate the differentiation of hMSCs into osteoblasts [21].

Here, the Raman micro-spectroscopy is used to find the molecular vibrations that are sensitive to the viability change of hUC-MSCs. The Raman spectra of hUC-MSCs with different cellular states were investigated, and the spectral differences between the cells with high viability $(>90 \%)$ and low viability $(<20 \%)$ were quantified using peak fitting and statistic t-test. It is found that the Raman peaks at 744, 877, and $1342 \mathrm{~cm}^{-1}$ show the most obvious changes as the cell viability decreases: the former two peaks, which correspond respectively to the vibration of $\mathrm{C}=\mathrm{O}$ out-of-the-plane bending in Thymine and the symmetric stretching of $\mathrm{C}-\mathrm{C}$ in lipids, are both roughly doubled; however, the latter peak, which corresponds to $\mathrm{C}-\mathrm{H}$ deformation in proteins, is reduced by ca. $30 \%$.

\section{Experimental}

\section{Isolation and culturing of hUC-MSCs}

hUC tissues were collected from voluntary donors, the healthy parturient women with welldeveloped fetus, who signed the consent form informed beforehand. The collection followed proper procedures according to the regulations of the Research Ethics Committees of the Chinese Academy of Medical Sciences and Beijing Union Medical College. The hUC tissues were then minced into $1 \mathrm{~mm}^{3}$ small fragments with sharp scissors. The fragments were washed thoroughly with PBS to remove contamination, and then treated with $0.075 \%$ collagenaseII and $0.25 \%$ trypsin (Sigma) at $37{ }^{\circ} \mathrm{C}$ for $30 \mathrm{~min}$. The digested mixture was passed through a $200 \mu \mathrm{m}$ filter to obtain cell suspensions. The dissociated cells were washed twice with PBS, planted on uncoated $25 \mathrm{~cm}^{2}$ culture flasks, and then cultured in Dulbecco's modified Eagle's medium with low gluocose (DMEM-LG/F-12, DF12; Gibco) and 10\% Fetal bovine serum (FBS, USA). The culture medium was replaced 2 days first and then after every 3 or 4 days. Daily progress of the cell culturing was monitored by phase-contrast microscopy. The cells were serially passaged and expanded in a humidified incubator at 37 ${ }^{\circ} \mathrm{C}$ with $5 \% \mathrm{CO}_{2}$.

hUC-MSCs with different viability were used for experiments. Decrease of the cell viability was induced by placing the cells under a condition of starvation, i.e. suspending in PBS at a low temperature of $4{ }^{\circ} \mathrm{C}$ for several days. The cell viability was accessed using the Trypan blue method in parallel with the Raman spectral measurements. The viability is defined as the ratio of the number of viable cells to the total number of all cells, and we call $>90 \%$ viability as "high viability" while $<20 \%$ viability as low viability.

\section{Raman micro-spectroscopy of hUC-MSCs with different viability}

The Raman spectra of hUC-MSCs with different viability were recorded using a Raman microspectrometer (LabRAM HR800, HORIBA Jobin Yvon, France), which is equipped with a 632.8 $\mathrm{nm}$ helium-neon laser for excitation. By means of the microscopic imaging provided by a TV camera, the Raman spectrum of each cell was measured by focusing the laser beam in the center of the cell. Under the laser power of $17 \mathrm{~mW}$ with a $50 \times$ objective, the signal was integrated for $100 \mathrm{~s}$. Each Raman spectrum was recorded in the range of $600-1800 \mathrm{~cm}^{-1}$. 


\section{Spectral processing and statistical analysis}

For spectral preprocessing, the background signal was subtracted from each spectrum, and a multipoint baseline was corrected in the whole spectral region. Spectra were then normalized to the peak intensity at $1448 \mathrm{~cm}^{-1}$ according to ref. [11] and [20].

In order to quantitatively characterize the Raman peaks, peak fitting was carried out in the spectral regions that show obvious differences between the cells with high and low viability by using the PeakFit software (v4.12, SeaSolve Software Inc., USA). The peak shape was taken to be Gaussian.

To statistically compare the intensity difference peak by peak, the Student's t-test was performed on each fitted Raman peak for two cell-groups (one group of 22 hUCMSCs with high viability and the other of 20 with low viability). The $\mathrm{p}$ values obtained from the t-test are used as the indicators of the differences. Since the $p$ value is defined as the probability of making a wrong judgment about a difference between the two sets of data, the smaller $p$ value implies the existence of the difference with higher possibility. As a rule of thumb, when $p<0.05$ the difference is meant to be statistical significance.

\section{Experimental results}

Fig. 4 shows the average Raman spectra of hUC-MSCs, where curve "a" is for high viable cells and curve " $b$ " for low viable cells. The Raman spectra show small standard deviations among the cells with the same viability (as presented as the gray shadows in curve "a" and " $b$ "). As can be seen, there are several Raman peaks that are already discernable, i.e. the $1448 \mathrm{~cm}^{-1}$ peak corresponding to $\mathrm{CH}$ deformation, the $1659 \mathrm{~cm}^{-1}$ peak to the protein amide $\mathrm{I}$, the $1003 \mathrm{~cm}^{-1}$ peak to the ring breathing of phenylalanine and the $1301 \mathrm{~cm}^{-1}$ peak to lipid $\mathrm{CH}_{2}$ twist. Curve " $c$ " plots the subtraction of " $\mathrm{b}$ " and " $a$ ", where visible differences can be observed, especially in the regions of $617-690,703-770,840-945,950-1020$, and $1250-$ $1360 \mathrm{~cm}^{-1}$, and at the peak of $1659 \mathrm{~cm}^{-1}$.

A Raman peak, which is uniquely defined by its spectral parameters including Raman shift, intensity, and full width at half maximum (FWHM), reveals the information about a specific molecular vibration. In order to extract the Raman peaks in the spectral regions where the high viable cells and low viable ones are distinguishing, the peak fitting analysis was performed. Fig. 5 shows the fitting results of curve "a" and " $b$ " in Fig.4, and Table 1 provides the extended peak assignments.

It can be seen from Fig. 5 that when the cell viability decreases, no obvious changes in Raman shift and FWHM are observed. However, the variations in peak intensity can be observed clearly. Apparently, as the cell viability decreases, the intensities of peaks at lower Raman shift $\left(<1000 \mathrm{~cm}^{-1}\right)$ increase while those of peaks at 1003 and $1342 \mathrm{~cm}^{-1}$ weaken. These results indicate that we can choose the peak intensity as a signature for detecting the cell viability transitions. As there are several peaks whose intensity change with the cell viability decrease, the Student's t-test is used for picking out the peaks with significant difference between the high viable and low viable cells, thus to find the molecular vibrations sensitive to the cell viability changes. The result of the t-test is described by the $p$ value, which actually reflects a reliability of the difference. Generally, $p<0.05$ represents a significant difference, and the lower the $p$ value is, the more reliable the difference will be. As listed in Table 2, there are about half of the peaks having significant differences in peak intensity as indicated by $p<0.05$. The intensity changes of these peaks with $p<0.05$ are illustrated in Fig. 
6. When the cell viability decreases, the intensity of peaks corresponding to nucleic acids at $621,643,667,744,900$, and $1010 \mathrm{~cm}^{-1}$ and to lipids at 719, 877, and $980 \mathrm{~cm}^{-1}$ increase, while those assigned to proteins at 1003, 1342, and $1659 \mathrm{~cm}^{-1}$ decrease. Especially, the most reliable spectral differences $(p<0.001)$ between the hUC-MSCs with high and low viability can be found in the $\mathrm{C}=\mathrm{O}$ out of plane bending in Thymine at $744 \mathrm{~cm}^{-1}, \mathrm{C}-\mathrm{C}$ symmetric stretching in lipids at $877 \mathrm{~cm}^{-1}$, and $\mathrm{C}-\mathrm{H}$ deformation in proteins at $1342 \mathrm{~cm}^{-1}$. In comparison of the case of high viability, the peak intensity of 744 and $877 \mathrm{~cm}^{-1}$ are both about doubled while that of $1342 \mathrm{~cm}^{-1}$ reduces by about $30 \%$ in the spectra of those with low viability. Herein, we suggest that the viability of hUC-MSCs can be characterized by intensities of these three peaks.

As mentioned in this paper, the peak intensity could be a signature for indicating the cell viability transitions. And the correlation with the peak intensity and the cell viability has been proved by our studies. To understand it further, the possible causes of the peak intensity changes are discussed briefly here. As been shown in Table 1, the Raman spectra of hUCMSCs are contributed from all major biological macromolecules including nucleic acids, proteins, lipids and carbohydrates. The intensity changes of the Raman peaks, especially for those highly sensitive to the cell viability transitions, can be understood from the interaction model between the intracellular reactive oxygen species (ROS, such as $\mathrm{OH}, \mathrm{O}_{2}^{-}$, and $\mathrm{H}_{2} \mathrm{O}_{2}$, which are the products of cell metabolism) and the biological macromolecules.

In healthy cells, ROS are typically generated at controlled rates. In contrast, the production of ROS will be elevated under stress conditions (e.g. cell apoptosis). This elevation will result in changes of many cellular components, such as DNA, proteins, and lipids, which will lead to further influence on the cell viability, metabolism, and growth. In addition to the findings shown in this paper, new research results from our lab on hUC-MSCs show that about half of the cells with low viability appear to be apoptotic (these results will be published elsewhere). As mentioned above, a large amount of ROS will stack in this situation. There were results suggesting that the excessive ROS will introduce attacks on intracellular biomolecules such as nucleic acids, proteins, and lipids [26]. So we believe that the peak intensity changes can be explained by the effect of excessive ROS, as follows. Because excessive ROS destroy the base-base stacking interactions, the hyperchromicity occurs resulting in the increasing intensity of Raman peaks, which correspond to nucleic acid bases at 744, 667, 643, and $621 \mathrm{~cm}^{-1}$. Moreover, the alterations in spatial structures of liposomes will inevitably change the micro-environment and spatial arrangement of chemical bonds within the molecular chains, which are probably responsible for the intensity variations of the Raman peaks assigned to lipids at 980, 877, and $719 \mathrm{~cm}^{-1}$. For proteins, the conformational changes in the secondary structures of proteins, such as the reduction of $a$-helix as indicated by the lower intensity at $1659 \mathrm{~cm}^{-1}$, were observed with as the cell viability decreases. These may be attributed to the attack of ROS that can lead to impairing or even breaking of hydrogen bonds, disulfide bonds and carbon-sulfur bonds, which play important roles in maintaining the structures of proteins. The structure variations of proteins are most likely to cause the micro-environmental changes of chemical bonds such as $\mathrm{C}-\mathrm{H}$ bonds, resulting in a change of their scattering cross sections. This could be a reason responsible for the peak intensity decrease of $1342 \mathrm{~cm}^{-1}$. Furthermore, ROS is able to induce protein degradation, which may also be a cause for the intensity decline of the peaks at 1003, 1342, and $1659 \mathrm{~cm}^{-1}$. It should be pointed out that given the diversity of cellular components and the complexity of molecular interactions, the above discussion is only preliminary and the further investigation is needed. 


\section{Conclusions}

In this study, we have shown that the relative intensity of Raman peaks at 1342, 877, and 744 $\mathrm{cm}^{-1}$, which correspond respectively to $\mathrm{C}-\mathrm{H}$ deformation in proteins, $\mathrm{C}-\mathrm{C}$ symmetric stretching in lipids, and $\mathrm{C}=\mathrm{O}$ out-of-the-plane bending in Thymine, are highly sensitive to the changes of hUC-MSCs viability. The intensity decrease of the peak at $1342 \mathrm{~cm}^{-1}$ and the intensity enhancement of the peaks at 877 and $744 \mathrm{~cm}^{-1}$ in the cells with low viability are related to the alterations of the secondary structures of proteins, the degradation of proteins, the structural modification of lipids, and the destruction of base-base stacking interactions in DNA. These changes could be understood by the interactions between the excessive intracellular ROS and the biomolecules.

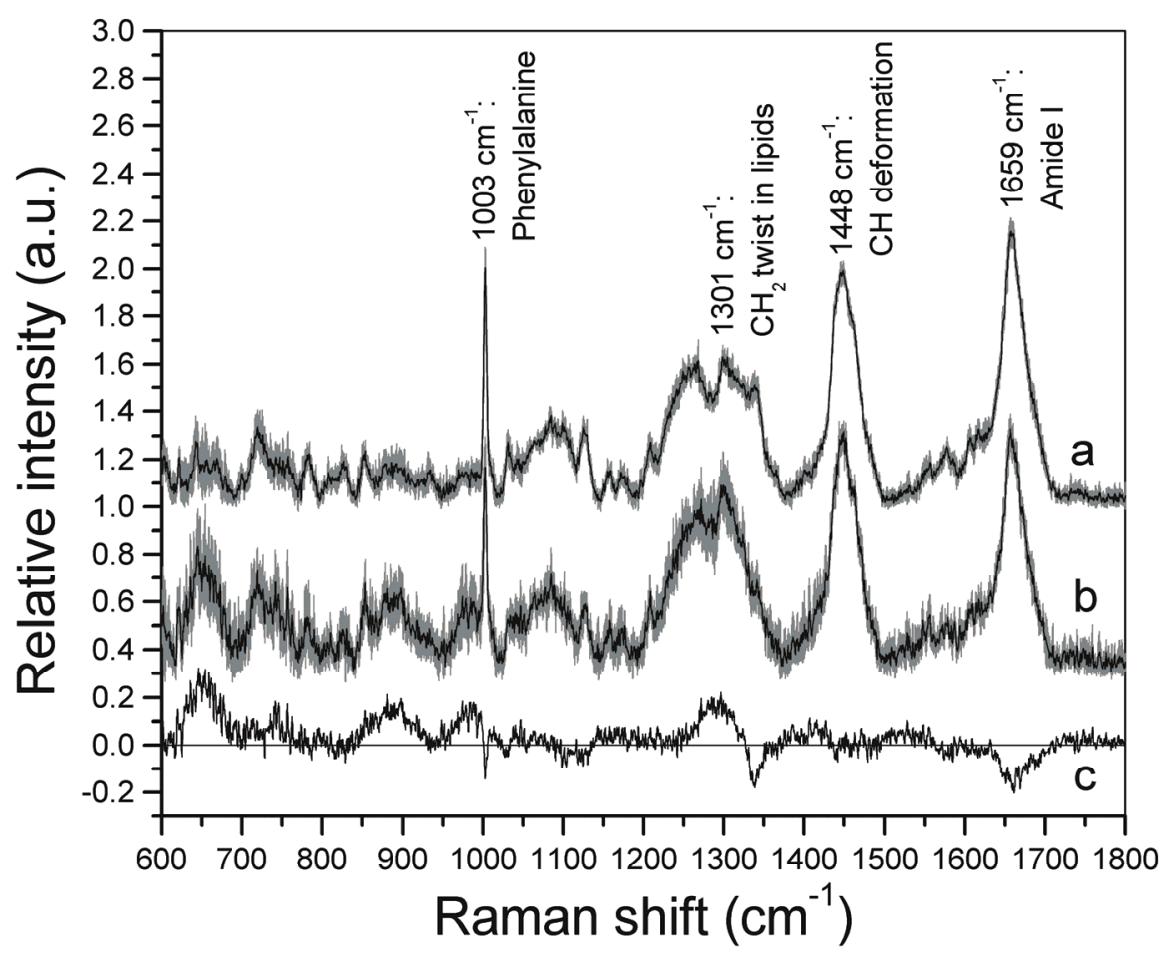

Fig. 4. Averaged Raman spectra from 22 hUC-MSCs with high viability (curve "a") and from 20 cells with low viability (curve " $b$ "). Shaded areas represent the standard deviations. The spectra were normalized to the intensity at $1448 \mathrm{~cm}^{-1}$. Difference spectrum (curve " $c$ ") was obtained by subtracting curve " $a$ " from curve " $b$ ". Spectra are shifted vertically for clarity. 


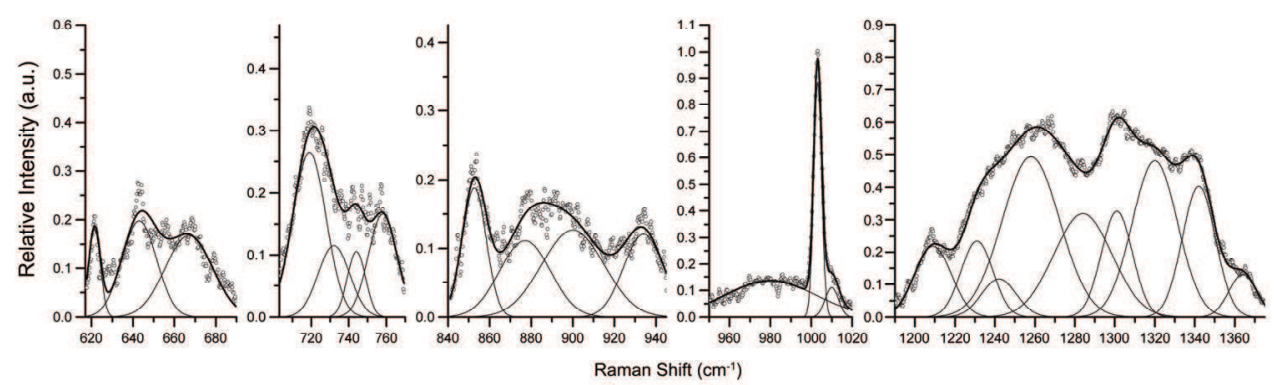

A. Peak fitting of the average Raman spectrum of hUC-MSCs with high viability

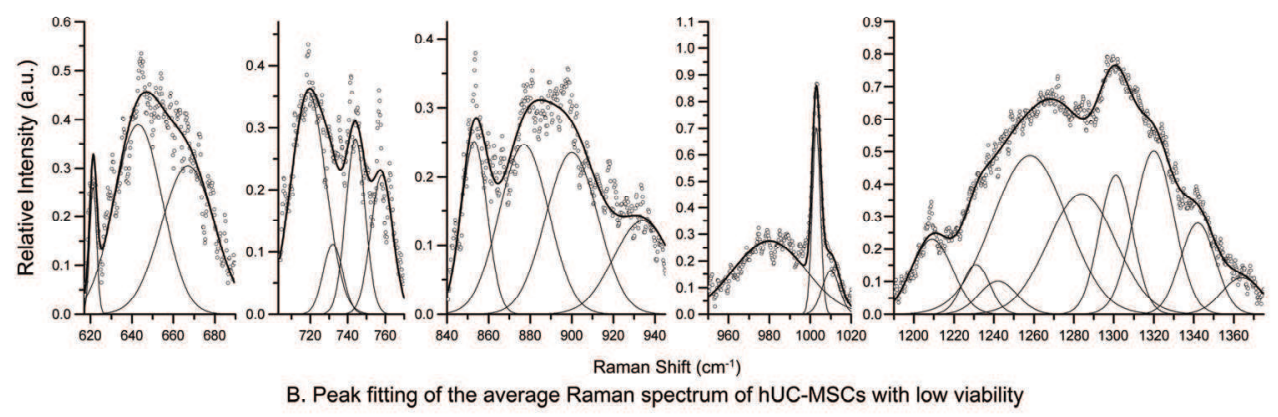

Fig. 5. Peak fitting of the averaged Raman spectra of hUC-MSCs with high viability (a) and low viability (b) in the spectral regions: 617 - 690, 703 - 770, 840 - 945, $950-1020$, and 1190 $1375 \mathrm{~cm}^{-1}$. Empty circles - experimental data, thin lines - fitted peaks, and thick lines - fitted curves.

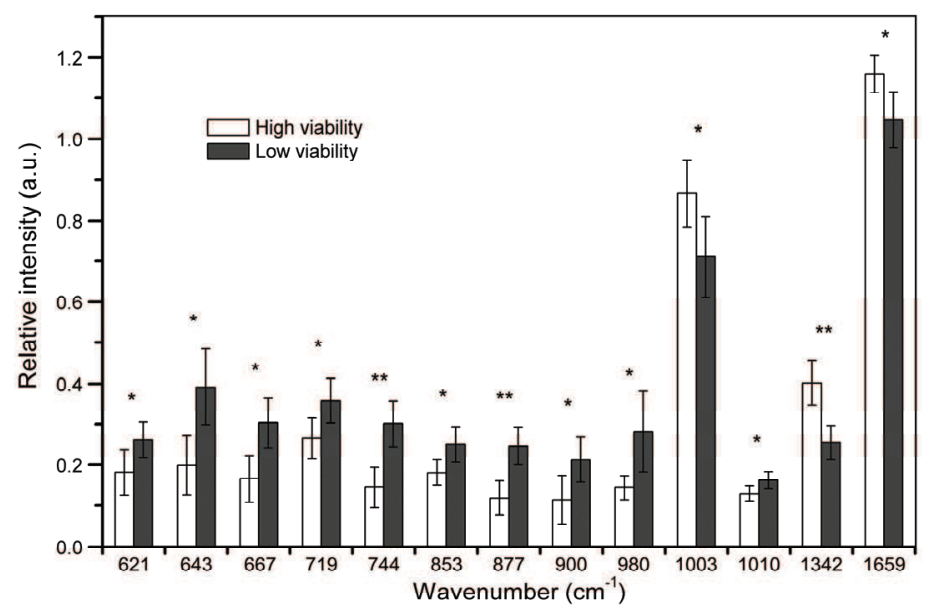

Fig. 6. Comparison of relative intensities of Raman peaks between hUC-MSCs with high and low viability. Block - averaged relative intensity, Bar - standard deviation. * means $p<0.05$, ${ }^{* *}$ means $p<0.001$ obtained by the Student's t-test analysis. 


\begin{tabular}{|c|c|}
\hline $\begin{array}{c}\text { Raman shift } \\
\left(\mathrm{cm}^{-1}\right)\end{array}$ & Assignment $[11,19,20,22-25]$ \\
\hline 621 & A 5-member ring deformation \\
\hline 643 & $\mathrm{~T}$ ring angle bend \\
\hline 667 & $\mathrm{G}$ ring breath \\
\hline 719 & $\mathrm{CN}^{+}\left(\mathrm{CH}_{3}\right)_{3}$ str in lipids \\
\hline 732 & A ring breath \\
\hline 744 & $\mathrm{~T} \mathrm{C}=\mathrm{O}$ out of plane bend \\
\hline 758 & Trp ring breath \\
\hline 784 & O-P-O str of DNA \\
\hline 811 & O-P-O str of RNA \\
\hline 827 & Tyr out of plane ring breath \\
\hline 853 & Tyr ring breath \\
\hline 877 & C-C symm str in lipids \\
\hline 900 & deoxyribose \\
\hline 934 & C-C bk str in proteins \\
\hline 980 & $=\mathrm{CH}$ bend in lipids \\
\hline 1003 & Phe symm ring breath \\
\hline 1010 & C-O str in deoxyribose \\
\hline 1031 & Phe \\
\hline 1064 & Chain C-C str in lipids \\
\hline 1083 & C-N str in proteins; Chain C-C str in lipids; C-O str in carbohydrates \\
\hline 1097 & O-P-O- str \\
\hline 1127 & C-N,C-C str in proteins \\
\hline 1157 & C-C,C-N str in proteins \\
\hline 1174 & Tyr,Phe \\
\hline 1209 & $\mathrm{C}-\mathrm{C}_{6} \mathrm{H}_{5}$ str of Phe \\
\hline 1231 & Amide III random coil \\
\hline 1242 & Amide III $\beta$-sheet \\
\hline 1258 & Amide III $\beta$-sheet \\
\hline 1284 & Amide III $\alpha$-helix \\
\hline 1301 & $\mathrm{CH}_{2}$ twist in lipids \\
\hline 1320 & $\mathrm{G} ; \mathrm{CH}$ def in proteins \\
\hline 1342 & $\mathrm{CH}$ def in proteins \\
\hline 1364 & $\mathrm{CH}_{3}$ symm str in lipids \\
\hline 1448 & $\mathrm{CH}$ def in DNA/RNA, proteins, lipids and carbohydrates \\
\hline 1659 & Amide I $\alpha$-helix \\
\hline
\end{tabular}

Abbreviations: asym, asymmetric; symm, symmetric; str, stretching; def, deformation; bk, backbone; A, Adenine; G, Guanine; C, Cytosine; T, Thymine; U, Uracil; Phe: phenylalanine; Tyr: tyrosine; Trp: tryptophan.

Table 1. Peak assignments for Raman spectra of hUC-MSCs 


\begin{tabular}{|c|c|c|}
\hline Region $\left(\mathrm{cm}^{-1}\right)$ & Wavenumber $\left(\mathrm{cm}^{-1}\right)$ & t-test $p$ value \\
\hline \multirow{3}{*}{$617-690$} & 621 & 0.0215 * \\
\hline & 643 & 0.0026 * \\
\hline & 667 & 0.0024 * \\
\hline \multirow{4}{*}{$703-770$} & 719 & 0.0122 * \\
\hline & 732 & 0.2833 \\
\hline & 744 & 0.0004 ** \\
\hline & 758 & 0.1163 \\
\hline \multirow{4}{*}{$840-945$} & 853 & 0.0101 * \\
\hline & 877 & $0.0005^{* *}$ \\
\hline & 900 & 0.0145 * \\
\hline & 934 & 0.4063 \\
\hline \multirow{3}{*}{$950-1020$} & 980 & 0.0173 * \\
\hline & 1003 & 0.0137 * \\
\hline & 1010 & 0.0166 * \\
\hline \multirow{10}{*}{$1190-1375$} & 1209 & 0.9462 \\
\hline & 1231 & 0.1886 \\
\hline & 1242 & 0.3941 \\
\hline & 1258 & 0.2832 \\
\hline & 1284 & 0.3884 \\
\hline & 1301 & 0.0722 \\
\hline & 1320 & 0.3496 \\
\hline & 1342 & 0.0004 ** \\
\hline & 1364 & 0.6455 \\
\hline & 1659 & 0.0073 * \\
\hline
\end{tabular}

*: $\mathrm{p}<0.05$ means significant differences; **: $\mathrm{p}<0.001$ means very significant differences.

Table 2. $\mathrm{p}$ values obtained by the statistical intensity comparison of the peaks in the region 617-690, 703-770, 840-945, 950-1020, 1190-1375 $\mathrm{cm}^{-1}$, and the peak at $1659 \mathrm{~cm}^{-1}$ between hUCMSCs with high and low viability.

7. Relations between Reactive Oxygen Species and Raman Spectral Variations of Human Umbilical Cord Mesenchymal Stem Cells with Different Viability

Mesenchymal stem cells (MSCs) are particularly attractive in cell-based therapy because of their distinct immunosuppressive properties and multi-differentiation capacity $[27,28]$. MSCs are traditionally found in the bone marrow. However, they can also be isolated from other 
tissues such as human umbilical cord. Human umbilical cord-derived MSCs (hUC-MSCs) have shown similar or even superior properties compared to bone marrow derived MSCs (BM-MSCs) including plastic adherence, specific surface markers, regenerative capability, collection convenience, safety, and potential of in vitro differential in certain lineages [29,30]. As a result of these advantages, hUC-MSCs have gained more attention in recent years.

Currently, hUC-MSCs are being explored as a promising candidate for therapeutic applications. $\mathrm{Wu}$ and Zhou [31,32] discussed the therapeutic potential of hUC-MSCs in cardiomyocyte regeneration, and their findings demonstrated that transplanted hUC-MSCs provide benefit in the restoration of cardiac function, suggesting that hUC-MSCs represent a source of stem cells for cell therapy and myocardial tissue engineering. Liao et al. reported that hUC-MSCs treatment could be an ideal strategy for cell-based therapy for central nervous system injury and disease [7]. Moreover, the impact of hUC-MSCs on liver fibrosis was also observed by Han and co-workers [33]. Recently, a series of experimental results indicate that hUC-MSCs are exceptional candidates for muscle repair [30], bone tissue engineering [34] and the treatment of rheumatoid arthritis (RA) [35].

The above data indicate that the hUC-MSCs hold great promise as therapeutic agents and as a tool for understanding the development of regeneration medicine. It is known that a large population of cells with high viability is fundamental to a successful cell-based therapy. Therefore, the detection of cell viability changes represents a key step for the population expansion and quality assurance of hUC-MSCs. As a label-free method, Raman spectroscopy is increasingly used in the study of stem cells [10, 19-21]. In our recently work [36], this technology was used to detect the viability transitions of hUC-MSCs. An encouraging finding was that the most significant Raman spectral variations associated with the cell viability decrease were at 1342,877 , and $744 \mathrm{~cm}^{-1}$, which implied a great potential for characterizing the cell viability changes. Considering the biochemical effects involved in the reactions of reactive oxygen species (ROS) [26], we concluded that these Raman spectral changes are probably due to the interaction between the intracellular ROS and biological macromolecules. However, given the diversity of cellular components and the complexity of molecular interactions, the reasons and the mechanisms of the Raman spectral variations remain unclear. In this context, several studies in our group are being carried out with the purpose of providing insights into the role of ROS involved in the cell viability transitions.

As an important aspect, the dependence of the Raman spectral variations on the yield of ROS in the cells has been studied in this paper. Here, we employ a ROS probe (DCFH-DA) to monitor the change of intracellular ROS level in hUC-MSCs as their viability declines. In addition, the Raman spectra of the cells with different viability are also recorded by Raman micro-spectroscopy. The results show that as the cell viability declines, the relative intensity variations of Raman peaks at 1342, 877, and $744 \mathrm{~cm}^{-1}$, and the relative yield variation of ROS in cells can be described by a same model(with different fitting parameters). Moreover, the correlations of these relative changes were evaluated by correlation coefficient method. It is found that they have perfect linear correlation coefficients respectively. This study further demonstrates that the relative yield variation of the ROS in hUC-MSCs with different viability can directly cause the relative intensity variation of Raman spectra in the cells.

\subsection{Intracellular ROS measurement}

The relative levels of ROS in hUC-MSCs with different viability were accessed using 2',7'dichlorofluorescin diacetate (DCFH-DA, Sigma), a fluorescent probe for intracellular ROS measurement. The DCFH-DA itself is non-fluorescent. It can be easily diffused through the 
cell membrane and be hydrolyzed by intracellular esterases to produce non-fluorescent 2',7'dichlorofluorescin (DCFH), which can no longer pass through the membrane so that the probe can easily be loaded into the cells. DCFH is then oxidized by ROS to generate fluorescent $2^{\prime}, 7^{\prime}$-dichlorofluorescein (DCF), whose fluorescence intensity is proportional to the amount of intracellular ROS [37, 38]. The cells were suspended in PBS at a density of 5.5 $\times 10^{5}$ cells $/ \mathrm{mL}$. After DCFH-DA was suspended at a final concentration of $20 \mu \mathrm{mol} / \mathrm{L}$, the cells were incubated for $40 \mathrm{~min}$ at $37^{\circ} \mathrm{C}$ for probe loading. -DCF fluorescence was then measured by a spectrometer (SpectraPro 300i, Acton, USA) equipped with a CCD detector (Spec-10, PI, USA). Ar+ laser (488 nm) was used for excitation, and the fluorescence was recorded in the range of 510-600 nm. In addition, same measurements of the DCFH-DA and PBS mixture (final concentration of the probe: $20 \mu \mathrm{mol} / \mathrm{L}$ ) without cells for fluorescent background acquisition were also performed.

\subsection{Experimental results}

ROS consist of a series of oxygen free radicals and their derivatives, such as $\mathrm{O}^{2-}, \mathrm{H}_{2} \mathrm{O}_{2}$, and - $\mathrm{OH}$, possess active chemical properties and high oxidation capability. They are generated from the sequential univalent reduction of oxygen involved in the cell metabolism [39, 40]. Since the cell itself has a highly efficient antioxidant system for eliminating ROS, the production and scavenging of ROS maintain a dynamic equilibrium under normal conditions. An appropriate amount of ROS is associated with many important physiological functions, such as biological messengers involved in cellular signal transduction [41, 42]. However, the production of intracellular ROS will greatly exceed the cellular antioxidant capacity under oxidative stress [43]. And ROS can act as the toxicants that easily react with biomolecules to damage their structures and functions and change their physical and chemical properties as Raman scattering [43-45].

Thus, to explore whether ROS play a role in the Raman spectral variations associated with the hUC-MSCs' viability transitions, we first monitored the change of intracellular ROS level as the cell viability decreased. As shown in Fig. 7, under the condition of cell starvation, the cell viability exhibits a linear decline with time. Therefore, the changes of the ROS level and the Raman spectra in cells as the cell viability decreases can be measured and discussed in the time dimension. By using ROS probe (DCFH-DA), the intracellular ROS levels were observed by the fluorescence spectra of the probe at different times. The results are shown in Fig. 8. The fluorescence spectra are from DCF, which is produced by the reactions of the probes with ROS. No fluorescence signals can be detected in the mixture solution of the probe molecules and PBS without the cells ("Background" in Fig. 8A), indicating that the fluorescence is originated only from the interaction of the probes with the intracellular ROS but not self-oxidation of the probes. Therefore, the relative intensities $(\mathrm{F})$ of the fluorescence in Fig. 8A will be directly proportional to the ROS level (ROS) in cells $[37,38]$ under the experimental conditions we designed. The relationship can be expressed as follows

$$
F=\varepsilon R O S
$$

where $\varepsilon$ is the proportional constant in this case. Fig. $8 \mathrm{~B}$ shows the column diagram of the relative fluorescence intensity at different times based on Fig. 8A. It is apparent that as the viability decreases, the level of ROS increases initially. It reaches a maximum value about 1.5 times higher than the initial time $(t=0)$ as the viability drops to about $36 \%$. As the viability continues to decrease, the ROS level experiences a decline. 
As mentioned above, a low ROS level under normal conditions is beneficial to the cells. Few oxidative damages by ROS should be taken into consideration in this case. However, when the production of ROS exceeds the cellular antioxidant capacity, oxidative damages will occur [39]. In other words, the excessive intracellular ROS lead to the oxidative damages. Considering this, we calculate the relative variation of ROS level $(\Delta \mathrm{ROS}(\mathrm{t}))$ in the cells at each measurement time $t$ based on the data in Fig. $8 \mathrm{~B}$, and take the first relative intensity at initial time $(t=0)$ as a normal value in the cells with normal viability. Therefore, the $\Delta R O S(t)$ ( $\mathrm{t}$ is the measurement time in Fig. 8B) can be calculated by the following expression.

$$
\Delta R O S(t)=\frac{F(t)-F(0)}{F(0)} \times 100 \%
$$

where $F(t)$ and $F(0)$ represent the relative fluorescence intensity at time $t$ and the initial time $(t=0)$, respectively. The change of $\triangle R O S$ with time is shown by the black squares in Fig. 9 .

Based on the data shown in Fig. 9, we seek to find a mathematical model to describe their change with time. It is found that a rational function (shown in Eq. (3)) can make a good fitting with the fitting degree $R^{2}=0.983$. Thus, the $\Delta R O S(t)$ can generally be expressed by the rational function as follows.

$$
\Delta R O S(t)=\frac{a+b t}{1+c t+d t^{2}}
$$

The data in Fig. 9 show that the ROS level is always higher than the initial $(t=0)$ in our observation period, implying that an accumulation of the excessive ROS in cells may occur as the cell viability decreases.

It should be noted that according to our experimental methods, the DCF fluorescence intensity is proportional to the amount of ROS generated in a short time period (40 min), which can be considered as a time point when compared to the entire experimental period (7 days). Thus, the data presented in Fig. 9 can only show the variation of "transient" ROS level, but not the yield of ROS during the cell viability decline. Since the oxidative damages resulting from excessive ROS can be irreversible [42], they thus rely on the cumulative effect of excessive ROS reacting with biomolecules. This means that the oxidative damages depend in part on the yield variation of ROS as the cell viability decreases. Having this in mind, we estimate the relative yield variation of ROS by integrating Eq. (3).

$$
\Delta \operatorname{ROS}_{\text {yield }}\left(t_{c}\right)=\int_{0}^{t_{c}} \frac{a+b t}{1+c t+d t^{2}} d t
$$

And thus

$$
=\frac{2 a d-b c}{d \sqrt{4 d-c^{2}}} \arctan \left(\frac{2 d t+c}{\sqrt{4 d-c^{2}}}\right)+\frac{b}{2 d} \ln \left(t^{2}+\frac{c}{d} t+\frac{1}{d}\right)
$$

Calling the values of the parameters $(a, b, c, d)$ from the best fitting result in Fig. 9 and considering the integral upper and lower limits, we can estimate the relative yield variation of ROS at any time point. The estimated $\Delta \operatorname{ROS}_{\text {yield }}(t)$ at $t=0 d, 1 d, 2 d, \ldots, 6 d$ is shown in Fig. 10 , which exhibits a nonlinear increase with time. In particular, it is found that the change of $\Delta \operatorname{ROS}_{\text {yield }}(\mathrm{t})$ can be exactly described by the logistic model (Eq. (6)) as indicated by the fitting 
degree $\mathrm{R}^{2}=0.999$. This model describes an S-type growth, i.e., the growth gradually slows down and eventually stops when the time goes to infinity.

$$
f(t)=\frac{\alpha}{1+\beta e^{-\gamma t}}
$$

The above results show that the relative yield variation of intracellular ROS increases continuously with the cell viability drop, suggesting that excessive ROS accumulate in cells and thus may attack the biomolecules as expected.

The excessive ROS are capable of attacking biomolecules, such as proteins, nucleic acids, and lipids, by a variety of reaction mechanisms including hydrogen abstraction, addition, etc. $[40,46,47]$. For example, ROS can react directly with the amino acid residues, causing the inactivation and denaturation of proteins [46]. Their attacks on DNA can also lead to the DNA bases modification and breaking of chemical bonds and certain strands [39, 47]. In addition, ROS induce the peroxidation of unsaturated fatty acids and cause oxidative damage to lipids $[39,40]$. This reaction is also an important mechanism that occurs with the oxidative damage to other biomolecules, such as malondialdehyde, an intermediate of peroxidation, that can cause the cross-linking of proteins [40, 46]. The oxidative damages from these reactions will undoubtedly lead to the structural and functional alterations of the biomolecules, and thus may cause changes in their Raman scattering.

Here we will pay attention to the dependence of the Raman spectral changes on ROS, but not the types of oxidative reactions that lead to the changes. That is, the relationship between Raman spectral variations and the relative yield variation of ROS in the cells need to be examined further in this paper. Raman spectra of hUC-MSCs with different viability (or at different time points) are shown in Fig. 11A. Raman spectral variations as the cell viability declines can be observed clearly. Thus we choose three vibration peaks that have been proven to be sensitive to the hUC-MSCs viability transitions [35]. They are protein $\mathrm{C}-\mathrm{H}$ deformation at $1342 \mathrm{~cm}^{-1}$, lipid C-C symmetric stretching at $877 \mathrm{~cm}^{-1}$, and thymine $\mathrm{C}=\mathrm{O}$ out-of-the-plane bending at $744 \mathrm{~cm}^{-1}$. Their relative intensity changes as a function of time are shown in Fig. 11B. It can be seen that the relative intensity of $1342 \mathrm{~cm}^{-1}$ decreases with time, while those of 877 and $744 \mathrm{~cm}^{-1}$ exhibit the reverse orientation. Further, we will focus on the variation of the relative intensity, because any deviations of these characteristic peak intensities from their normal values will indicate the drop of cell viability [35].

Based on the data shown in Fig. 11b and the above method used to discuss ROS (Eq. (2)), the relative peak intensity variations $\left(\Delta \mathrm{I}_{\mathrm{w}}(\mathrm{t})\right)$ of the three peaks can be calculated by the following expression.

$$
\Delta I_{w}(t)=\frac{\left|I_{w}(t)-I_{w}(0)\right|}{I_{w}(0)} \times 100 \%
$$

where $I_{w}(t)$ and $I_{w}(0)$ represent the relative intensity of the peak $w$ at the time $t$ and the initial time $(t=0)$, respectively. The calculated results are shown in Fig. 12.

To investigate the change tracks of $\Delta \mathrm{I}_{1342}(\mathrm{t}), \Delta \mathrm{I}_{877}(\mathrm{t}), \Delta \mathrm{I}_{744}(\mathrm{t})$ and their relationship to $\Delta \operatorname{ROS}_{\text {yield }}(\mathrm{t})$, we also try to use the logistic model (Eq. (6)) to fit the data points in Fig.12. As presented in Fig. 12, it is interesting to find that the logistic model is also suitable for describing the changes of $\Delta \mathrm{I}_{1342}(\mathrm{t}), \Delta \mathrm{I}_{877}(\mathrm{t})$, and $\Delta \mathrm{I}_{744}(\mathrm{t})$ indicated by the high fitting degrees of $0.993,0.986$, and 0.996 , respectively. However, the parameters $(\alpha, \beta, \gamma)$ obtained by fitting 
$\Delta \mathrm{I}_{1342}(\mathrm{t}), \Delta \mathrm{I}_{877}(\mathrm{t})$, and $\Delta \mathrm{I}_{744}(\mathrm{t})$ differ from each other, and also show large differences from those of fitting $\triangle$ ROS $_{\text {yield }}(t)$. This seems reasonable and understandable from the complexity and diversity of ROS reactions. There are many mechanisms showing that ROS interact with biomolecules directly or indirectly [40,46,47]. The attack of ROS seems impossible to cause the synchronous and homogeneous alterations in all the biomolecules. The differences in the molecular response (rate, scale, sensitivity) to the ROS attack and the types of reactions will inevitably affect the reaction rates (of the reactant depletion and the product formation) in the cells. And also, the formation of the excessive ROS themselves will lead to the component changes in the cells. All complications make the fitting parameters or the fitting curves of $\Delta \mathrm{I}_{\mathrm{w}}(\mathrm{t})$ of some individual Raman peaks $\mathrm{w}$ show larger deviation from those of $\Delta \operatorname{ROS}_{\text {yield }}(t)$. That is, it is almost impossible for all $\Delta \mathrm{I}_{\mathrm{w}}(\mathrm{t})$ to correlate with $\Delta \operatorname{ROS}_{\text {yield }}(\mathrm{t})$ in exact linearity. Furthermore, it should be mentioned that the parameter a is primarily determined by the maximum of the relative intensity (or yield) variation and is basically independent on the fitting curves that is defined by the shape parameters $\beta$ and $\gamma$. The differences between $\Delta \mathrm{I}_{744}(\mathrm{t})$ and $\Delta \mathrm{ROS}_{\text {yield }}(\mathrm{t})$ in the two shape parameters are the largest (Fig. $12 C)$ in all the $\Delta \mathrm{I}_{\mathrm{W}}(\mathrm{t})$, thus the linear correlation between their fitting curves is the lowest, suggesting that the reaction mechanism relating to this peak increase would be very complicated. In fact, the ROS in the cells are consumed through many channels. Therefore, we may have a better result if using the sum of the relative intensity variations of all characteristic Raman peaks (here we have three peaks) measured at the same time. The relative intensity total variation as a function of time $\left(\Delta \mathrm{I}_{\text {total }}(\mathrm{t})\right)$ is expressed as follows.

$$
\Delta I_{\text {total }}(t)=\sum_{w} \Delta I_{w}(t)
$$

where $\Delta \mathrm{I}_{\mathrm{w}}(\mathrm{t})$ is the relative intensity variation of the peak $\mathrm{w}$ at time $\mathrm{t}$. Here we have $\mathrm{w}=$ 1342,877 , and $744 \mathrm{~cm}^{-1}$. The calculated results are shown in Fig. 12d, and the fitting curve (with Eq. (6)) shows a perfect fitting degree $\left(\mathrm{R}^{2}=0.999\right)$. All the fitting constants for $\Delta \mathrm{I}_{\text {total }}(\mathrm{t})$ are much better than those for any other $\Delta \mathrm{I}_{\mathrm{w}}(\mathrm{t})$ compared with those for $\Delta \mathrm{ROS}_{\text {yield }}(\mathrm{t})$. Thus, the fitting curves of $\Delta \mathrm{I}_{\text {total }}(\mathrm{t})$ and $\Delta \operatorname{ROS}_{\text {yield }}(\mathrm{t})$ are basically similar, and the linear relationship between them should be better than others.

To further quantitatively evaluate the relationship, the correlation coefficient $r$ is employed to describe the correlations of $\Delta \mathrm{I}_{1342}(\mathrm{t}), \Delta \mathrm{I}_{877}(\mathrm{t}), \Delta \mathrm{I}_{744}(\mathrm{t})$, and $\Delta \mathrm{I}_{\text {total }}(\mathrm{t})$ with $\Delta$ ROS yield $_{(\mathrm{t})}(\mathrm{t}$ respectively. The $\mathrm{r}$ is calculated as follows [48].

$$
r=\frac{\sum_{i=1}^{n}\left(X_{i}-\bar{X}\right)\left(Y_{i}-\bar{Y}\right)}{\sqrt{\sum_{i=1}^{n}\left(X_{i}-\bar{X}\right)^{2} \times \sum_{i=1}^{n}\left(Y_{i}-\bar{Y}\right)^{2}}}
$$

where, $X_{i}, Y_{i}(i=1,2, \ldots, n)$ express independent and dependent variables respectively; $r$ describes the linear correlation of the two variables and takes the value in $-1 \leq \mathrm{r} \leq 1$. The larger $|\mathrm{r}|$ is, the higher the correlation will be. The calculation results show that the correlation coefficients for correlated $\Delta \mathrm{I}_{1342}(\mathrm{t}), \Delta \mathrm{I}_{877}(\mathrm{t}), \Delta \mathrm{I}_{744}(\mathrm{t})$, and $\Delta \mathrm{I}_{\text {total }}(\mathrm{t})$ to $\Delta \mathrm{ROS}_{\text {yield }}(\mathrm{t})$ are 0.980, 0.985, 0.973, and 0.987, respectively. For clarity, these correlations are shown in Fig. 13. The high $\left|\mathrm{r}_{\mathrm{w}}\right|$ values provide a further evidence to confirm that the changes of the three relative peak intensities linearly correlate to the relative yield variation of ROS, especially at 
the beginning of the cell viability decrease. Taken together, the results demonstrate that the oxidative damages induced by excessive intracellular ROS lead to the Raman spectral variations associated with the cell viability decline. In addition, the $\Delta \mathrm{I}_{\text {total }}(\mathrm{t})$ shows the best linear relationship to the $\Delta \mathrm{ROS}_{\text {yield }}(\mathrm{t})$, while that of individual Raman peak intensity appears lower linear correlation coefficient, indicating that the corresponding biochemical reactions of intracellular ROS have much more complicate mechanisms and needs further study.

\section{Conclusions}

Herein, we reveal that the relative yield variation of ROS in hUC-MSCs with different viability can directly lead to the relative intensity variations of the three characteristic Raman peaks at 1342,877 , and $744 \mathrm{~cm}^{-1}$ in the cells, according to their perfect linear correlation coefficients of $0.980,0.985$, and 0.973 , respectively. Our findings demonstrate that the excessive intracellular ROS can result in the almost linear variation of the relative Raman peak intensity in hUC-MSCs as the cell viability declines. These results would be very useful for understanding the mechanisms of Raman spectral changes in the cells.

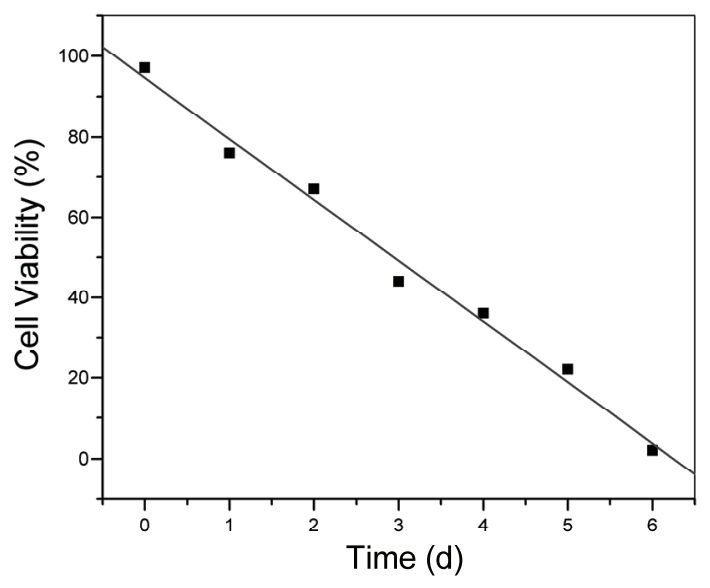

Fig. 7. Change of cell viability as a function of time (cells are placed under starvation condition). The line represents the linear fitting. 

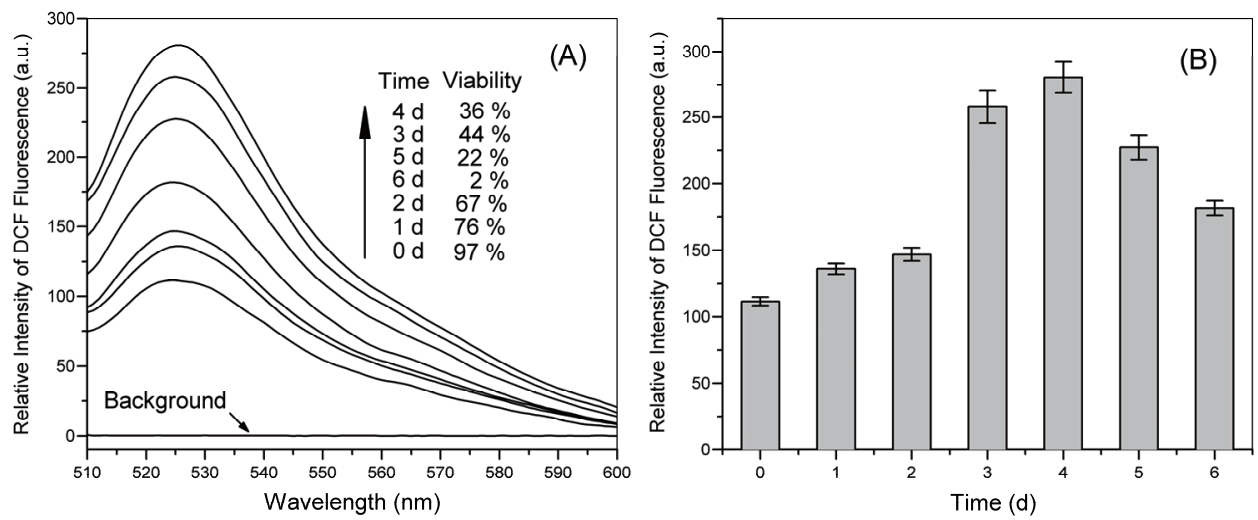

Fig. 8. Change of intracellular ROS level with time. (A) Fluorescence spectra of DCF at different times corresponding to different cell viability. (B) Histogram showing averaged relative intensities of DCF fluorescence and standard deviation.

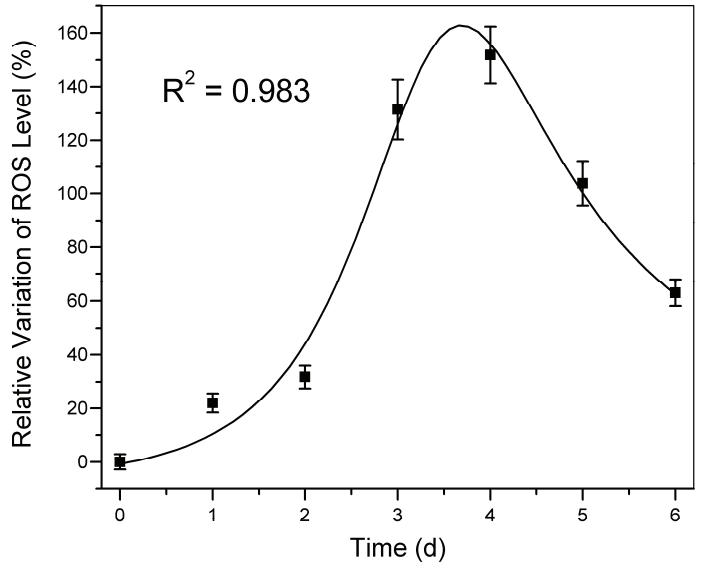

Fig. 9. Relative variation of ROS level as a function of time. The data points are from Eq. (2). The line represents the best fitting using a rational function (Eq. (3)), with the fitting degree $R^{2}=0.983$ and the parameters $a=-0.80747, b=6.77836, c=-0.50330, d=0.07387$. 


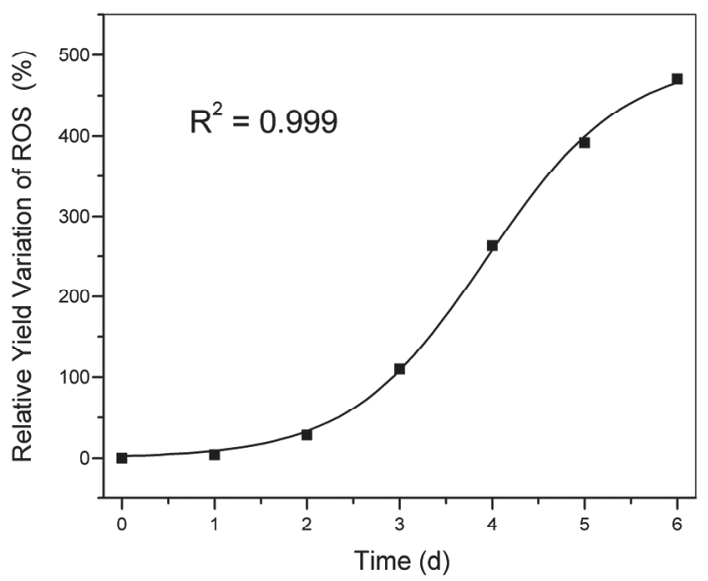

Fig. 10. Change of relative yield variation of ROS as a function of time. The line represents the best fitting using logistic model (Eq. (6)), with the fitting degree $R^{2}=0.999$ and the parameters $\alpha=494.247, \beta=208.473, \gamma=1.35624$.
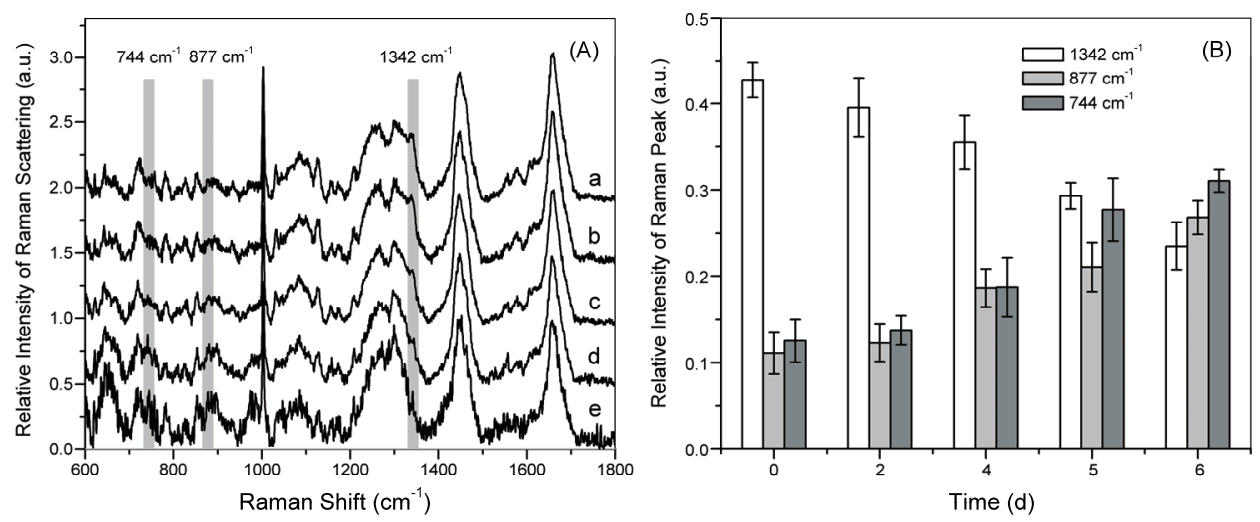

Fig. 11. (A) Raman spectra of hUC-MSCs with different cell viability: (a) cell viability $97 \%, t$ $=0$ (b) $67 \%, t=2 d$ (c) $36 \%, t=4 d$ (d) $22 \%, t=5 d$ (e) $2 \%, t=6 d$. All spectra are normalized to the peak intensity at $1448 \mathrm{~cm}^{-1}$. Spectra are shifted vertically for clarity. (B) Changes of the relative peak intensities at 1342,877 , and $744 \mathrm{~cm}^{-1}$ as a function of time. 


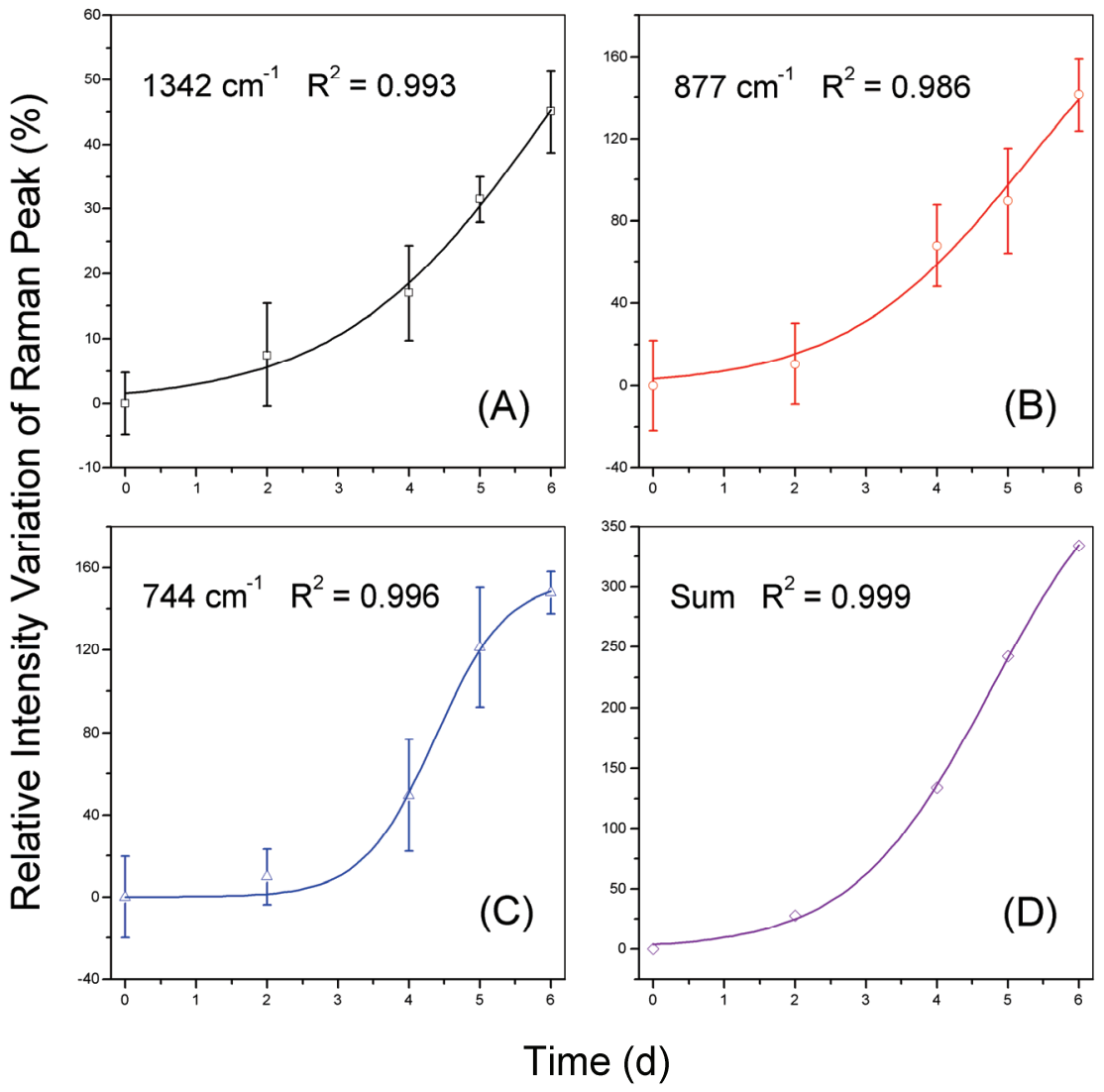

Fig. 12. Relative changes of Raman peak intensity variations at (A) 1342 , (B) 877, (C) $744 \mathrm{~cm}^{-1}$, and their sum (D) as a function of time. The lines represent the best fitting using logistic model (Eq. (6)). (A) Fitting degree $R^{2}=0.993$, the parameters $\alpha=91.3853, \beta=58.5466, \gamma=$ 0.67544. (B) $R^{2}=0.986, \alpha=216.993, \beta=62.1816, \gamma=0.78485$. (C) $R^{2}=0.996, \alpha=154.484, \beta=$ 5191.54, $\gamma=1.95969$. (D) $R^{2}=0.999, \alpha=430.957, \beta=122.328, \gamma=1.00860$. 


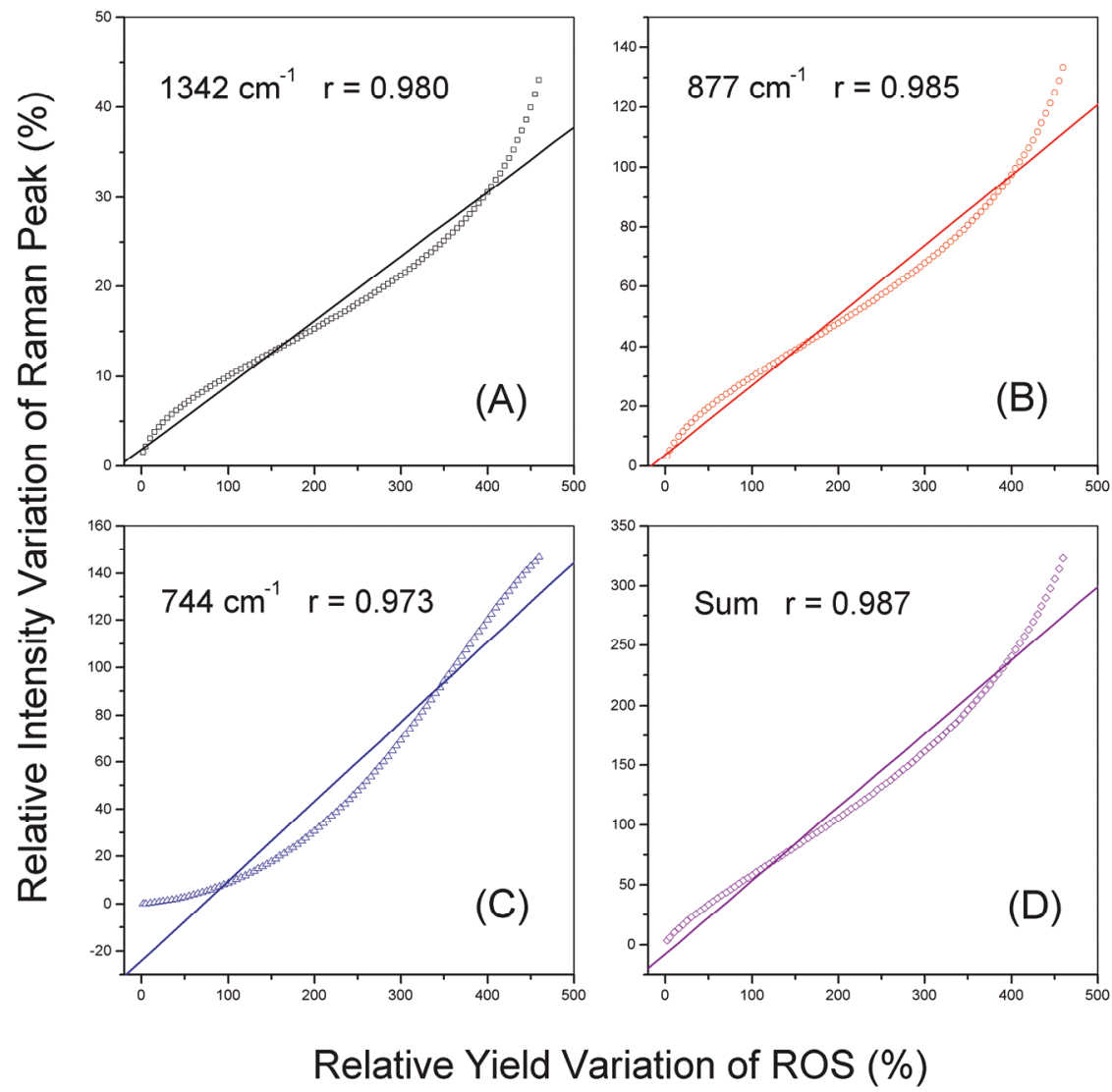

Fig. 13. Correlations between the relative yield variation of ROS and the relative intensity variations of Raman peaks at (A) 1342, (B) 877, (C) $744 \mathrm{~cm}^{-1}$ and their sum (D) $\Delta I_{\text {total }}(t)$. The lines represent the linear fittings for the changes of $\Delta I_{1342}(t), \Delta I_{877}(t), \Delta I_{744}(t)$, and $\Delta I_{\text {total }}(t)$ as a function of $\Delta \mathrm{ROS}_{\text {yield }}(t)$, with the correlation coefficients of $0.980,0.985,0.973$, and 0.987 , respectively.

\section{Summary}

Mesenchymal stem cells (MSCs) are pluripotent progenitor cells derived from the mesoderm. They are particularly suitable for cell-based therapy because of their different immunosuppressive properties and multi-differentiation capacity. The main source of MSCs is bone marrow. In addition, recent progress revealed that human umbilical cord derived mesenchymal stem cells (hUC-MSCs) could be an alternative source ideal for MSCs. Comparing to bone marrow-derived MSCs (BM-MSCs), hUC-MSCs have exhibited similar or even superior properties such as plastic adherence, specific surface markers, regenerative capability, collection convenience, safety, and potential for in vitro differential in certain lineages. These advantages make hUC-MSCs a promising candidate for therapeutic applications in recent years. 
As is known, a large population of cells in sustained high profitability is fundamental to successful cell-based therapy. Therefore, monitoring the variation in cell viability is an important step for the population expansion and quality assurance of hUC-MSCs. Right now there are a number of methods including biological assays and optical techniques available to handle this task. Among these techniques, Raman spectroscopy is a label-free method that allows for continued analysis. Moreover, it is proven that Raman spectroscopy has the potential to offer new and unique optical markers for cytological analysis. Currently this technology is increasingly used in the studies of stem cells.

In this work, Raman micro-spectroscopy is used to monitor the variation of hUC-MSCs viability. The Raman spectra of hUC-MSCs with different cellular states are investigated. Using peak fitting and statistical t-test, the Raman peaks are extracted with obvious differences between cells of different viability. Most significant changes $(p<0.001)$ have been found for the out-of-plane bending of $\mathrm{C}=\mathrm{O}$ in thymine at $744 \mathrm{~cm}^{-1}$, symmetric stretching of C-C in lipids at $877 \mathrm{~cm}^{-1}$, and deformation of C-H in proteins at $1342 \mathrm{~cm}^{-1}$. As the cell viability decreases, the intensity of the peak at $1342 \mathrm{~cm}^{-1}$ is reduced, whereas those of the peaks at 877 and $744 \mathrm{~cm}^{-1}$ are enhanced. Based on these results, we propose that the viability of hUCMSCs can be characterized by these three peaks.

Given the biochemical effects involved in the reactions of reactive oxygen species (ROS), we conclude that the changes of Raman peak intensity could be explained by the interactions between excessive intracellular ROS and biological macromolecules. However, considering the diversity of cellular components and the complexity of molecular interactions, the exact reasons and mechanisms remain unclear. In this context, we further investigate the dependence of the Raman spectral variations on the yield of ROS in the cells for understanding the mechanism. Here we employ a ROS probe (DCFH-DA) to monitor the change of intracellular ROS level in hUC-MSCs as their viability declines. The results we obtained show that as the cell viability decreases, the relative intensity variations of the Raman peaks at $1342 \mathrm{~cm}^{-1}, 877 \mathrm{~cm}^{-1}$, and $744 \mathrm{~cm}^{-1}$, and the relative yield variations of ROS in cells can be described by the same model function (besides different fitting parameters used). In addition, the correlations of these relative changes were assessed by correlation coefficient method. Perfect linear correlation coefficients of 0.969, 0.982, and 0.975 were found. Our results further demonstrate that the relative yield variations of ROS in hUCMSCs with different viability directly cause the relative intensity variations of Raman spectra in the cells. The results would be very useful for understanding the mechanism of the Raman spectral changes in the cells and the investigation of the basis for the application of Raman scattering in the measurement of stem cell viability.

\section{Acknowledgements}

We would like to thank Prof. Y. Zhao and Mrs. L.W. Duan for assistance in Raman spectral measurements. This work is supported by Tianjin Municipal Science and Technology Commission (No. 08ZCDFGX09400), and National Natural Science Fund Committee of China (No. 60508004 and No. 60778043).

\section{References}

[1] Motaln H, C Schichor and TT Lah. Human mesenchymal stem cells and their use in cellbased therapies. Cancer 116:2519-2530 (2010) 
[2] Mitchell KE, ML Weiss, BM Mitchell, P Martin, D Davis, L Morales, B Helwig, M Beerenstrauch, K Abou-Easa, T Hildreth, D Troyer and S Medicetty. Matrix cells from Wharton's jelly form neurons and glia. Stem Cells 21:50-60 (2003).

[3] Wang HS, SC Hung, ST Peng, CC Huang, HM Wei, YJ Guo, YS Fu, MC Lai and CC Chen. Mesenchymal stem cells in the Wharton's jelly of the human umbilical cord. Stem Cells 22:1330-1337 (2004).

[4] Sarugaser R, D Lickorish, D Baksh, MM Hosseini and JE Davies. Human umbilical cord perivascular (HUCPV) cells: A source of mesenchymal progenitors. Stem Cells 23:220-229 (2005).

[5] Baksh D, R Yao and RS Tuan. Comparison of proliferative and multilineage differentiation potential of human mesenchymal stem cells derived from umbilical cord and bone marrow. Stem Cells 25:1384-1392 (2007).

[6] Li G, XA Zhang, H Wang, X Wang, CL Meng, CY Chan, DTW Yew, KS Tsang, K Li, SN Tsai, SM Ngai, ZC Han, MC Lin, ML He and HF Kung. Comparative proteomic analysis of mesenchymal stem cells derived from human bone marrow, umbilical cord, and placenta: Implication in the migration. Proteomics 9:20-30 (2009).

[7] Liao WB, J Zhong, JX Yu, J Xie, YJ Liu, L Du, SG Yang, PX Liu, J Xu, JM Wang, ZB Han and ZC Han. Therapeutic benefit of human umbilical cord derived mesenchymal stromal cells in intracerebral hemorrhage rat: Implications of anti-inflammation and angiogenesis. Cell Physiol Biochem 24:307-316 (2009).

[8] Wu KH, SG Yang, B Zhou, WT Du, DS Gu, PX Liu, WB Liao, ZC Han and YL Liu. Human umbilical cord derived stem cells for the injured heart. Med Hypotheses 68:94-97 (2007).

[9] Lu LL, YJ Liu, SG Yang, QJ Zhao, X Wang, W Gong, ZB Han, ZS Xu, YX Lu, D Liu, ZZ Chen and ZC Han. Isolation and characterization of human umbilical cord mesenchymal stem cells with hematopoiesis-supportive function and other potentials. Haematologica 91:1017-1026 (2006).

[10] Chan JW and DK Lieu. Label-free biochemical characterization of stem cells using vibrational spectroscopy. J Biophotonics 2:656-668 (2009).

[11] Notingher I, S Verrier, S Haque, JM Polak and LL Hench. Spectroscopic study of human lung epithelial cells (A549) in culture: Living cells versus dead cells. Biopolymers 72:230-240 (2003).

[12] Notingher I, G Jell, U Lohbauer, V Salih and LL Hench. In situ non-invasive spectral discrimination between bone cell phenotypes used in tissue engineering. J Cell Biochem 92:1180-1192 (2004).

[13] Verrier S, I Notingher, JM Polak and LL Hench. In situ monitoring of cell death using Raman microspectroscopy. Biopolymers 74:157-162 (2004).

[14] Short KW, S Carpenter, JP Freyer and JR Mourant. Raman spectroscopy detects biochemical changes due to proliferation in mammalian cell cultures. Biophys J 88:4274-4288 (2005).

[15] Owen CA, J Selvakumaran, I Notingher, G Jell, LL Hench and MM Stevens. In vitro toxicology evaluation of pharmaceuticals using Raman micro-spectroscopy. J Cell Biochem 99:178-186 (2006).

[16] Swain RJ and MM Stevens. Raman microspectroscopy for non-invasive biochemical analysis of single cells. Biochemical Society Transactions 35:544-549 (2007).

[17] Swain RJ, G Jell and MM Stevens. Non-invasive analysis of cell cycle dynamics in single living cells with Raman micro-spectroscopy. J Cell Biochem 104:1427-1438 (2008).

[18] Chan J, S Fore, S Wachsmann-Hogiu and T Huser. Raman spectroscopy and microscopy of individual cells and cellular components. Laser \& Photon Rev 2:325-349 (2008). 
[19] Notingher I, I Bisson, JM Polak and LL Hench. In situ spectroscopic study of nucleic acids in differentiating embryonic stem cells. Vib Spectrosc 35:199-203 (2004).

[20] Chan JW, DK Lieu, T Huser and RA Li. Label-free separation of human embryonic stem cells and their cardiac derivatives using Raman spectroscopy. Anal Chem 81:13241331 (2009).

[21] Chiang HK, FY Peng, SC Hung and YC Feng. In situ Raman spectroscopic monitoring of hydroxyapatite as human mesenchymal stem cells differentiate into osteoblasts. J Raman Spectrosc 40:546-549 (2009).

[22] Azrad E, D Zahor, R Vago, Z Nevo, R Doron, D Robinson, LA Gheber, S Rosenwaks and I Bar. Probing the effect of an extract of elk velvet antler powder on mesenchymal stem cells using Raman microspectroscopy: Enhanced differentiation toward osteogenic fate. J Raman Spectrosc 37:480-486(2006).

[23] Mohamed TA, IA Shabaan, WM Zoghaib, J Husband, RS Farag and Abd El-Nasser MA Alajhaz. Tautomerism, normal coordinate analysis, vibrational assignments, calculated IR, Raman and NMR spectra of adenine. J Mol Struct 938:263-276 (2009).

[24] Singh JS. FTIR and Raman spectra and fundamental frequencies of biomolecule: 5Methyluracil (thymine). J Mol Struct 876:127-133 (2008).

[25] Nishimura Y, M Tsuboi, T Nakano, S Higuchi, T Sato, T Shida, S Uesugi, E Ohtsuka and M Ikehara. Raman diagnosis of nucleic acid structure: Sugar-puckering and glycosidic conformation in the guanosine moiety. Nucleic Acids Res 11:1579-1588 (1983).

[26] Beckman KB and BN Ames. The free radical theory of aging matures. Physiol Rev 78:547-581 (1998).

[27] A. J. Nauta and W. E. Fibbe, Immunomodulatory properties of mesenchymal stromal cells, Blood 110, 3499-3506 (2007).

[28] A. Uccelli, L. Moretta, and V. Pistoia, Immunoregulatory function of mesenchymal stem cells, Eur. J. Immunol. 36, 2566-2573 (2006).

[29] C. Knocaefe, D. Balci, B. B. Hayta, and A. Can, Reprogramming of human umbilical cord stromal mesenchymal stem cells for myogenic differentiation and muscle repair, Stem Cells Rev. 6, 512-522 (2010).

[30] K. Chen, D. Wang, W. T. Du, Z. B. Han, H. Ren, Y.Chi, S. G. Yang, D. L. Zhu, F. Bayard, and Z. C. Han, Human umbilical cord mesenchymal stem cells hUC-MSCs exert immunosuppressive activities through a PGE2-dependent mechanism, Clin. Immunol. 135, 448-458 (2010).

[31] K. H. Wu, B. Zhou, C. T. Yu, B. Cui, S. H. Lu, Z. C. Han, and Y. L. Liu, Therapeutic potential of human umbilical cord derived stem cells in a rat myocardial infarction model, Ann. Thorac. Surg. 83, 1491-1498 (2007).

[32] K. H. Wu, X. M. Mo, B. Zhou, S. H. Lu, S. G. Yang, Y. L. Liu, and Z. C. Han, Cardiac potential of stem cells from whole human umbilical cord tissue, J. Cell. Biochem. 107, 926-932 (2009).

[33] H. Y. Ren, Q. J. Zhao, T. Cheng, S. H. Lu, Z. Chen, L. Meng, X. F. Zhu, S. G. Yang, W. Xing, Y. D. Xiao, Q. Ren, Y. Chi, D. S. Gu, R. C. Yang, and Z. C. Han, No contribution of umbilical cord mesenchymal stromal cells to capillarization and venularization of hepatic sinusoids accompanied by hepatic differentiation in carbon tetrachloride-induced mouse liver fibrosis, Cytotherapy 12, 371-383 (2010).

[34] L. Zhao, E. F. Burguera, H. H. K. Xu, N. Amin, H. Ryou, and D. D. Arola, Fatigue and human umbilical cord stem cell seeding characteristics of calcium phosphatechitosan-biodegradable fiber scaffolds, Biomaterials 31, 840-847 (2010). 
[35] Y. Y. Liu, R. Mu, S. Y. Wang, L. Long, X. Liu, R. Li, J. Sun, J. P. Guo, X. P. Zhang, J. Guo, P. Yu, C. L. Li, X. Y. Liu, Z. Y. Huang, D. P. Wang, H. Li, Z. F. Gu, B. Liu, and Z. G. $\mathrm{Li}$, Therapeutic potential of human umbilical cord mesenchymal stem cells in the treatment of rheumatoid arthritis, Arthritis Res. Ther. 12, R210 (2010).

[36] H. Bai, P. Chen, H. Fang, L. Lin, G. Q. Tang, G. G. Mu, W. Gong, Z. P. Liu, H. Wu, H. Zhao, and Z. C. Han, Detecting viability transitions of umbilical cord mesenchymal stem cells by Raman micro-spectroscopy, Laser Phys. Lett. 8, 78-84 (2011).

[37] S. I. Choi, C. S. Jeong, S. Y. Cho, and Y. S. Lee, Mechanism of apoptosis induced by apigenin in HepG2 human hepatoma cells: involvement of reactive oxygen species generated by NADPH oxidase, Arch. Pharm. Res. 30, 1328-1335 (2007).

[38] H. M. Shen, C. Y. Shi, Y. Shen, and C. N. Ong, Detection of elevated reactive oxygen species level in cultured rat hepatocytes treated with aflatoxin B1, Free Radic. Biol. Med. 21, 139-146 (1996).

[39] U. Bandyopadhyay, D. Das, and R. K. Banerjee, Reactive oxygen species: Oxidative damage and pathogenesis, Curr. Sci. 77, 658-666 (1999).

[40] D. Yin and K. Chen, The essential mechanisms of aging: Irreparable damage accumulation of biochemical side-reactions, Exp. Gerontol. 40, 455-465 (2005).

[41] B. D'Autréaux and M. B. Toledano, ROS as signalling molecules: mechanisms that generate specificity in ROS homeostasis, Nat. Rev. Mol. Cell Biol. 8, 813-824 (2007).

[42] A. Gomes, E. Fernandes, and J. L. F. C. Lima, Fluorescence probes used for detection of reactive oxygen species, J. Biochem. Biophys. Methods 65, 45-80 (2005).

[43] W. T. Chang, H. L. Lin, H. C. Chen, Y. M. Wu, W. J. Chen, Y. T. Lee, and L. Liau, Realtime molecular assessment on oxidative injury of single cells using Raman spectroscopy, J. Raman Spectrosc. 40, 1194-1199 (2009).

[44] D. M. Zhang, D. P. Jiang, M. Yanney, S. Zou, and A. Sygula, Ratiometric Raman spectroscopy for quantification of protein oxidative damage, Anal. Biochem. 391, 121-126 (2009).

[45] Y. M. Xu, Z. X. Zhou, H. Y. Yang, Y. Xu, and Z. Y. Zhang, Raman spectroscopic study of microcosmic photodamage of the space structure of DNA sensitized by Yangzhou haematoporphyrin derivative and Photofrin II, J. Photochem. Photobiol. B: Biol. 52, 30-34 (1999).

[46] G. L. Li and D. Z. Yin, Chem. Life 27, 516-520 (2007). (in Chinese)

[47] M. Dizdaroglu, P. Jaruga, M. Birincioglu, and H. Rodriguez, Free radical-induced damage to DNA: mechanisms and measurement, Free Radic. Biol. Med. 32, 11021115 (2002).

[48] Y. Liu, P. Chen, F. Zhang, L. Lin. G.-Q. Tang, and G.-G. Mu, Laser Phys. Lett. 6, 465 (2009). 


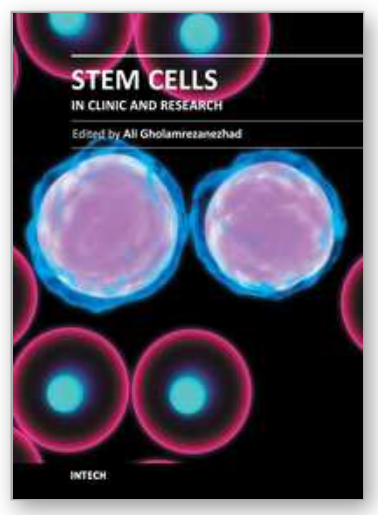

\author{
Stem Cells in Clinic and Research \\ Edited by Dr. Ali Gholamrezanezhad
}

ISBN 978-953-307-797-0

Hard cover, 804 pages

Publisher InTech

Published online 23, August, 2011

Published in print edition August, 2011

Based on our current understanding of cell biology and strong supporting evidence from previous experiences, different types of human stem cell populations are capable of undergoing differentiation or trans-differentiation into functionally and biologically active cells for use in therapeutic purposes. So far, progress regarding the use of both in vitro and in vivo regenerative medicine models already offers hope for the application of different types of stem cells as a powerful new therapeutic option to treat different diseases that were previously considered to be untreatable. Remarkable achievements in cell biology resulting in the isolation and characterization of various stem cells and progenitor cells has increased the expectation for the development of a new approach to the treatment of genetic and developmental human diseases. Due to the fact that currently stem cells and umbilical cord banks are so strictly defined and available, it seems that this mission is investigationally more practical than in the past. On the other hand, studies performed on stem cells, targeting their conversion into functionally mature tissue, are not necessarily seeking to result in the clinical application of the differentiated cells; In fact, still one of the important goals of these studies is to get acquainted with the natural process of development of mature cells from their immature progenitors during the embryonic period onwards, which can produce valuable results as knowledge of the developmental processes during embryogenesis. For example, the cellular and molecular mechanisms leading to mature and adult cells developmental abnormalities are relatively unknown. This lack of understanding stems from the lack of a good model system to study cell development and differentiation. Hence, the knowledge reached through these studies can prove to be a breakthrough in preventing developmental disorders. Meanwhile, many researchers conduct these studies to understand the molecular and cellular basis of cancer development. The fact that cancer is one of the leading causes of death throughout the world, highlights the importance of these researches in the fields of biology and medicine.

\title{
How to reference
}

In order to correctly reference this scholarly work, feel free to copy and paste the following:

P.Chen, F.Zhang, L.Lin, H.Bai, L.Zhang, G.Q.Tang, H.Fang, G.G.Mu, W. Gong, Z. P. Liu, Z. B. Han, H. Zhao and Z. C. Han (2011). Raman Spectroscopy for Noninvasive Monitoring of Umbilical Cord Mesenchymal Stem Cells Viability Transitions, Stem Cells in Clinic and Research, Dr. Ali Gholamrezanezhad (Ed.), ISBN: 978-953307-797-0, InTech, Available from: http://www.intechopen.com/books/stem-cells-in-clinic-and-research/ramanspectroscopy-for-noninvasive-monitoring-of-umbilical-cord-mesenchymal-stem-cells-viability-tra

\section{INTECH}

open science | open minds 


\section{InTech Europe}

University Campus STeP Ri

Slavka Krautzeka 83/A

51000 Rijeka, Croatia

Phone: +385 (51) 770447

Fax: +385 (51) 686166

www.intechopen.com

\section{InTech China}

Unit 405, Office Block, Hotel Equatorial Shanghai No.65, Yan An Road (West), Shanghai, 200040, China

中国上海市延安西路65号上海国际贵都大饭店办公楼 405 单元 Phone: +86-21-62489820

Fax: +86-21-62489821 
(C) 2011 The Author(s). Licensee IntechOpen. This chapter is distributed under the terms of the Creative Commons Attribution-NonCommercialShareAlike-3.0 License, which permits use, distribution and reproduction for non-commercial purposes, provided the original is properly cited and derivative works building on this content are distributed under the same license. 